\title{
AÇÃO EDUCATIVA DO ENFERMEIRO NA PREVENÇÃO DE DOENÇAS SEXUALMENTE TRANSMISSÍVEIS: UMA INVESTIGAÇÃO A PARTIR DAS ADOLESCENTES
}

\author{
Educative action of nurse in the prevention of sexually transmitted \\ diseases: an investigation with the adolescents \\ Acción educativa da enfermería en la prevención de enfermedades \\ sexualmente transmisibles: una investigación a partir de las adolescentes
}

Eveline Pinheiro Beserra ${ }^{1}$

Patrícia Neyva da Costa Pinheiro²

Maria Grasiela Teixeira Barroso ${ }^{3}$

\section{RESUMO}

Trata-se de uma pesquisa qualitativa com objetivo de investigar a sexualidade das adolescentes a partir da ação educativa do enfermeiro na prevenção de doenças sexualmente transmissíveis. Realizada numa escola pública em Fortaleza, Ceará, com 10 meninas entre 14 e 16 anos, no período de agosto a novembro de 2007. Adotou-se como método o Círculo de Cultura, que foi formado por cinco encontros. Utilizaram-se a observação e a observação participante para coleta dos dados, que foram registrados no diário de campo. Observou-se que as meninas associam o sexo à sexualidade de forma predominante e que tinham pouca compreensão das vulnerabilidades que estavam expostas numa prática sexual desprotegida. Evidenciou-se que a execução do Círculo de Cultura permitiu que as meninas explorassem e discutissem sobre diversos temas que englobavam sua sexualidade, e que era um momento para ações de educação em saúde com a meta de isentá-las de riscos.

Palavras-chave: Adolescência. Doenças Sexualmente Transmissíveis. Enfermagem.

\begin{abstract}
It's a qualitative research, with the objective to investigate the adolescents sexuality from the educative action of nurse in the prevention of Sexual Transmissible Diseases. It was done in a public school in Fortaleza - Ceará with 10 girls aged between 14 and 16, from August to November, 2007. Five meetings were carried out, using the circle of culture and registered in the field diary through the observation and the participating observation. It was observed that girls consider the association of having sex to sexuality and they have little comprehension of the vulnerabilities that they were exposed to in an unprotected sexual act. It was observed that the execution of the circle of culture allowed them to explore and discuss about many subjects that involved their sexuality and it was also a moment to make actions of health education with the objective to prevent them from the risks.
\end{abstract}

Keywords: Adolescence. Sexually Transmitted Diseases. Nursing

\section{Resumen}

Se trata de una investigación cualitativa, con el objetivo de investigar la sexualidad de las adolescentes a partir de una acción educativa da enfermería en la prevención de enfermedades sexualmente transmisibles. Realizada en una escuela pública en For taleza-Ceará con 10 niñas entre catorce y dieciséis años, en el periodo de agosto hasta noviembre de 2007. Fueron realizados cinco encuentros adoptándose el Círculo de cultura y se registraron en el diario de campo a través de la observación y de la observación participante. Se observó que las niñas asocian sexo a sexualidad de forma predominante y que tenían poca comprensión de las vulnerabilidades a que estaban expuestas con una práctica sexual desprotegida. Se evidenció que la ejecución del círculo de cultura permitió que las niñas explorasen y discutiesen sobre diversos temas que englobaban su sexualidad, y también fue un momento para acciones de educación en salud con la meta de eximirlas de riesgos.

Palabras clave: Adolescencia. Enfermedades sexualmente transmisibles. Enfermería 


\section{INTRODUÇ̃̃O}

A adolescência é um período marcado de vulnerabilidades, uma vez que é uma etapa da vida com conflitos em âmbito social, psicológico, físico, entre outros. A descoberta do prazer sexual muitas vezes se dá nessa época, quando há a necessidade de ações de educação em saúde para orientar esses adolescentes sobre os riscos de contaminação com doenças sexualmente transmissíveis (DST). Nesse contexto, a sexualidade é um aspecto importante de ser analisado, pois a percepção desse tema é formulado a partir de experiências cotidianas desses jovens ${ }^{1}$, e há a necessidade de aprofundamento sobre ele para uma compreensão efetiva.

A estratégia básica para o controle da transmissão das DST e do HIV é a prevenção pelos meios que permitam atividades educativas que focalizem os riscos inerentes a uma relação sexual desprotegida, a mudança no comportamento e a adoção do preservativo ${ }^{2}$.

Um fato marcante na adolescência, em nossa sociedade, é o início prematuro da vida sexual, contribuindo para o aumento da suscetibilidade de infecção pelas DST como também uma gravidez indesejada, fato ainda mais preocupante quando relacionada à maternidade precoce. Pelas diversas formas de comunicação possíveis, como, por exemplo, diálogos, mídia, folder, fórum de discussão, é importante explicar aos adolescentes, os que possuem vida sexual ativa ou não, a necessidade do uso de preservativo nas relações sexuais. Uma das formas de comunicação que deve ser trabalhada com o jovem é o diálogo, para que se possam vencer os tabus que estão relacionados com o sexo e diminuir o número de jovens em estado de vulnerabilidade diante das DST/AIDS ${ }^{3}$.

As ações de educativas voltadas para o adolescente devem contemplar a saúde sexual e reprodutiva, dúvidas e medos acerca da temática abordada e, além de tudo, a identificação do contexto cultural o qual está inserido, pois as estratégias devem condizer com sua realidade de modo a serem efetivas.

Vista a necessidade da inserção da educação em saúde em todos os âmbitos da juventude, cabe aos profissionais a sensibilização para trabalhar com esse objetivo: educar para uma maior qualidade de vida, contemplando as especificidades da adolescência. Desta forma, a Enfermagem destaca-se por estar intimamente ligada ao ser humano e preocupada com o seu bem-estar, enquadra-se no desafio de ações em Educação em Saúde que permitam incentivar os jovens à reflexão crítica de sua realidade. É fundamental que a Enfermagem coloque no centro dos debates sobre saúde discussões acerca de técnicas as quais podem ser submetidas a grupos específicos, ou seja, pessoas contextualizadas numa mesma realidade. Portanto, este estudo se propôs a investigar a sexualidade das adolescentes a partir da ação educativa do enfermeiro na prevenção de doenças sexualmente transmissíveis.

\section{METODOLOGIA}

Trata-se de um estudo qualitativo exploratório, realizado numa Escola de Ensino Fundamental e Médio em Fortaleza, Ceará, Brasil. 0 número de participantes foi intencional para contemplar o objetivo do estudo, totalizando 10 meninas, entre 14 e 16 anos, obedecendo aos seguintes critérios de inclusão: estarem devidamente matriculados na escola e desejarem participar da pesquisa. 0 período da investigação foi de agosto a novembro de 2007. 0 presente estudo usou como instrumentos e procedimentos: observação, observação participante, diário de campo e Círculo de Cultura. Este foi utilizado para promover Educação em Saúde, pois se trata de uma metodologia que permite aos adolescentes dialogarem abertamente sobre sua vida ${ }^{4}$. 0 Círculo de Cultura favorece 0 aprendizado rápido, contextualizado à realidade dos educandos, no qual existe uma inter-relação que proporciona liberdade e crítica acerca do assunto abordado, resultando em um grupo mais participativo nos debates, diálogos e trabalhos, e também é utilizado como um itinerário de pesquisa ${ }^{5}$.

0 Círculo de Cultura foi composto por cinco encontros com duração de cinqüenta minutos, abordando os seguintes temas: adolescência, sexualidade, doenças sexualmente transmissíveis, vida sexual segura e uso do preservativo. 0 primeiro encontro foi constituído por palavras geradoras, que são ditas pelos próprios participantes do grupo. Essas palavras significam o contexto real no qual os educandos vivem, sendo essenciais para a condução do Círculo de Cultura e para a realização dos encontros posteriores, como também na elaboração das fichas de cultura, que buscam retratar figuras para favorecer uma discussão. 0 segundo encontro envolveu a integração das palavras geradoras, quando se dialogaram temas do interesse das jovens. No terceiro encontro houve abordagem das doenças sexualmente transmissíveis. No quarto encontro, ocorreram discussões diversas, refletindo-se sobre temas que contemplavam a saúde sexual e reprodutiva das adolescentes. 0 quinto encontro focou a avaliação do processo. 0 círculo foi composto também por um animador que mediava as discussões, organizava e coordenava o grupo, de modo a proporcionar a participação dos educandos durantes os diálogos ${ }^{6}$. Esse animador também realizava o registro dos diálogos suscitados, abstraindo seus conteúdos para, em seguida, serem analisados à luz da literatura pertinente sobre 0 assunto.

Os encontros foram realizados informalmente e conduzidos através de contatos repetitivos. Vale ressaltar que essa interação valoriza a participação de todos no estudo, envolvendo-os no processo ${ }^{7}$. Foram respeitados os aspectos éticos e legais que envolvem pesquisas com seres humanos, conforme a Resolução 196196 do Conselho Nacional de Saúde. Foi também esclarecido às jovens que a recusa em participar da pesquisa não lhe causaria nenhum prejuízo ao acesso à escola pesquisada e sobre a necessidade da assinatura do Termo de Consentimento Livre e Esclarecido, tanto pelas adolescentes como pelos responsáveis. Ressalta-se que 0 estudo foi submetido à apreciação do Comitê de Ética em Pesquisa da Universidade Federal do Ceará e aprovado na reunião do dia 26 de julho de 2007, número do protocolo 171/ 07; e somente após autorização deu-se início ao estudo. 


\section{RESULTADOS E DISCUSSÕES}

Primeiro encontro e Segundo encontro: Palavras geradoras e Integração entre palavras geradoras

Em forma de círculo, iniciava-se a primeira oficina do Círculo de Cultura. Essa forma de organizar as cadeiras permite que todos se olhem, interajam entre si, criando uma horizontalidade nas discussões em que todos são iguais nos diálogos.

Para iniciarmos o diálogo, foi inserida a seguinte reflexão: 0 que vocês pensam quando associam adolescência e sexualidade? As palavras geradoras foram surgindo: relação sexual, namoro, "ficar", gravidez, doença, esquecimento da camisinha, problemas de uma gravidez precoce. Elas foram essenciais para a elaboração das oficinas posteriores.

Ainda sobre as palavras geradoras ditas pelas meninas, observou-se, predominantemente, que a questão da sexualidade está direcionada aos atos sexuais ou ao relacionamento a dois, visto que o conceito de sexualidade é mais amplo, sendo algo que constitui o ser humano e que está estreitamente relacionado ao âmbito pessoal, como também ao resultado da cultura e das relações sociais estabelecidas pelo sexo masculino e feminino ${ }^{8}$.

Elas mostraram, também, preocupação diante da gravidez precoce, por já observarem na sociedade que a responsabilidade de uma gravidez recai prioritariamente ao sexo feminino. Este fato ocasiona conseqüências que refletem na perda de liberdade, adiamento ou comprometimento dos projetos de estudos, limitação de perspectivas de ingresso no mercado de trabalho, aproveitamento pleno das oportunidades para completo desenvolvimento pessoal ${ }^{9}$.

De forma dialógica, inseriu-se a reflexão de como a jovem percebe sua sexualidade, e algumas responderam: Vejo como normal. Ficando grávida na adolescência. Namorando, ficando...Sem o conceito esclarecido de sexualidade, as adolescentes caracterizaram a sexualidade como uma etapa de desenvolvimento do indivíduo. Outras relataram a gestação.

A questão da sexualidade é sempre um grande desafio no universo do adolescente, vivenciar mudanças em seu corpo e, no caso das meninas, a menarca e a possibilidade de gravidez. Essa questão, em algumas comunidades, torna-se um padrão social que mostra rito de passagem para a vida adulta ${ }^{10}$.

Sobre a percepção da família diante da sexualidade da adolescente, elas relataram: $A$ mãe diz para menina: não faça, porque você ficará difamada. A virgindade é o valor que conta. Para os meninos, tudo é liberado. Eu acho que minha mãe faz é sair para deixar meu irmão com uma menina lá em casa. Falar com minha mãe sobre sexo, não dá, ela vai é brigar comigo. Pelo discurso, elas continuaram caracterizando a sexualidade como sinônimo de sexo e demonstraram como é o relacionamento dos pais com as filhas. Esse relacionamento muitas vezes se resume à proibição do sexo, ausência de diálogo, tons de ameaça, evitando, assim, que se flua uma conversa em família. Direcionam-se valores à virgindade feminina, e, em contrapartida, para os meninos, estimula-se a prática sexual.

Diante desse fato, deve existir uma educação voltada para a liberdade, que tenha como um direito de ser, para capacitar a formação de uma consciência crítica sobre 0 assunto ${ }^{11}$.
Inserindo no diálogo o relacionamento das jovens com os seus irmãos, observou-se no estudo rivalidades: Eu não posso falar nada com meu irmão, ele é fofoqueiro. Essa frase dita por uma jovem foi repetida por outras, reafirmando, assim, a falta de confiança no irmão. Visto que alguns irmãos têm essa rivalidade e compactuam com a criação dos pais em relação à educação sexual da irmã, provavelmente são possíveis imitadores desta postura com suas futuras filhas.

0 gênero imprime normas, valores, percepções, representações que permeiam a vida do sujeito, legitimando sua identidade, visto assim, a sua influência no comportamento do indivíduo ${ }^{12}$.

Numa reflexão sobre relacionamento de amizade, algumas jovens afirmaram o quanto é perigoso conversar assuntos pessoais com amigas, devido ao risco de um dia contarem para outra pessoa um segredo anteriormente dito. Após esse comentário, surgiu uma situação imaginária durante o diálogo: "Se sua menstruação atrasar, você primeiro conta para quem?" A resposta foi unânime: "para a amiga". Esse fato acontece porque muitas jovens não têm uma relação aberta com os progenitores.

Alguns pais conversam, mas é de forma superficial; as colegas são as pessoas mais indicadas pela jovem para abordar esse assunto primeiramente, uma vez que, para elas, é mais fácil conversar sobre sexo.

$\mathrm{Na}$ discussão de como a escola percebe a sexualidade da jovem, foi dito: Não dão orientação sobre gravidez, doenças. Novamente, e como observado em todo o encontro, a percepção de sexualidade se dá somente como sexo. Então, construiu-se o seu conceito, e elas passaram a refletir sobre sexualidade com outro significado.

Ainda sobre a reflexão: "como a escola percebe a sexualidade da jovem", relatou-se: A escola não deixa a gente entrar de saia curta e top. Os professores não falam sobre esse assunto. Eu já fiz um trabalho sobre DST para apresentar na escola que eu estudava.

A escola sabe da complexidade da sexualidade do jovem, mas nem sempre a contempla integralmente. A escola constrói o saber, que é um poder; não podemos mudar a história sem 0 conhecimento, para o qual é necessário educar para interferir nos sujeitos, situando o saber para os excluídos de forma crítica, tornando-os capazes de refletir sobre sua vida ${ }^{13}$. A escola é um pilar na integração entre saúde e educação, uma vez que a interdisciplinaridade de ações permite que seja estabelecida uma intervenção efetiva e um crescimento mútuo das partes.

Nesse segundo encontro, foram apresentadas as fichas de cultura, retratando a primeira um casal abraçado, a segunda um casal de criança iniciando um beijo, a terceira uma adolescente grávida. No primeiro encontro, observou-se a correlação da sexualidade com a relação a dois, por isso essas fichas retratavam, predominantemente, casais.

0 início do segundo encontro deu-se pela apresentação da ficha de cultura. Ao mostrar a primeira ficha, foi dito que era um namoro, surgindo palavras que retratavam sentimentos referentes aos relacionamentos a dois, como: companheirismo, 
sinceridade, amizade, amor, emergindo também o termo "ficar", definido por uma jovem como um namoro aberto, em que "ninguém é de ninguém". Foi importante a visão da jovem sobre relacionamento para identificarmos fatores de riscos e intensificarmos orientações para prevenção de DST.

Ainda sobre a discussão sobre "ficas", relataram que depende do casal se o "ficar" significa somente beijos e abraços ou estende-se ao ato sexual. Se a menina der liberdade, o menino se aproveita. Onde vai parar, depende dos dois.Uma vez fiquei com um menino que não fazia nada, aí eu perguntei: e aí, vai ficar só olho no olho? Os meninos são safados, avançados, mas têm meninas que são assim também. Diante do exposto, a sexualidade precisa ser discutida abertamente com o jovem.

A compreensão dos seus conceitos e suas idéias são fatos importantes para ações de intervenções em saúde, a fim de proporcionar maior qualidade de vida. A questão do relacionamento a dois pode está relacionada ao início da vida sexual. Assim, algumas das causas desse início, descrito em um estudo, é o desejo pelo parceiro, vontade de sentir prazer, curiosidade, mas predominante pelo sentimento de amor e paixão ${ }^{9}$.

A segunda ficha de cultura mostrava um casal de crianças. Deu-se o início da discussão sobre a precocidade observada no meio social. Alguns pontos foram ditos: (...) a criança não vive a infância. Você precisa ver minha irmã de sete anos, ela é mais esperta do que eu. Vai para Lagoa e fica com todos os meninos de lá. Ainda sobre precocidade, houve a discussão de que namorar cedo implica no início de uma vida sexual precoce. Algumas jovens falaram que isso não é regra, mas que poderia acontecer.

Surgiu no diálogo o comentário: Quando eu saio só com meu namorado, o povo já malda que vou fazer alguma coisa. Até namorar no carro, falam. As adolescentes demonstraram que pessoas conhecidas comentam sobre os casais de namorados, atentando ao comportamento deles, e não se preocupam em orientá-los quando julgam que eles realizam um compor tamento de risco para sua saúde.

As atitudes dos adolescentes suscitam julgamento por ser uma idade de descobertas. 0 jovem tem que viver seus relacionamentos consciente de que está sendo observado e que a sociedade impõe condutas estereotipadas. Os adolescentes que assumem práticas afetivo-sexuais distintas dos padrões socialmente desejáveis são vítimas da discriminação, implicando a manutenção destes preconceitos por meio dos envolvimentos sociais ${ }^{14}$.

Através de uma reflexão crítica, é importante orientar as jovens para que reflitam sobre atitudes que demonstrem responsabilidades por si próprias e pelo seu companheiro, não para a sociedade, mas para elas mesmas trabalharem sua autonomia. A responsabilidade do jovem por suas escolhas e as conseqüências de seus atos devem ser abordadas de forma clara, desde o momento em que ele passa para a adolescência ${ }^{15}$.

No diálogo, foi discutido sobre o momento ideal para terem a primeira relação, algumas falaram sobre a obtenção de maturidade, planejamento, orientação sobre métodos anticoncepcionais e prevenção de DST. Então, diante dessa discussão, foi questionado: "Por que se vêem tantas meninas grávidas?" Algumas respostas obtidas: Algumas é porque não sabem, outras fazem no impulso, tá lá e faz, tá nem aí.

A necessidade de maturidade para iniciar a vida sexual é impor tante para estar consciente de que é uma ação que pode implicar doenças sexualmente transmissíveis e gravidez precoce, sendo necessário intervir com ações de Educação em Saúde antes do início da vida sexual, porém também deve ser trabalhada com jovens que têm vida sexual ativa, por meio do diálogo que os conscientizem.

Na terceira ficha de cultura havia uma adolescente grávida. Discutimos sobre esse fato, e as meninas relataram: Tem menina que pensa logo no aborto, mas é um crime, pode morrer se fizer ou deixar de engravidar. Um filho muda a vida de qualquer pessoa.

A jovem deve estar esclarecida sobre as modificações que uma gravidez acarretaria na sua vida, são duas únicas as condutas a serem tomadas nessa situação: o aborto ou ter o filho, porém ambas envolvem conseqüências emocionais fortes ${ }^{15}$. Pelo discurso das participantes do grupo, observou-se que elas têm consciência da repercussão de uma gravidez precoce na vida de uma adolescente e das conseqüências que poderiam ocorrer.

Diante das discussões, houve a necessidade de ser dialogado sobre a anatomia feminina e a masculina, a partir do seguinte questionamento: Quando o esperma entra, sai pela urina? Diante desse questionamento, vimos que as jovens não conhecem sua anatomia e iniciam a vida sexual sem conhecerem seu próprio corpo, necessitando de informações que as capacite exercer sua sexualidade de forma saudável.

Diante do encontro realizado, observou-se que o Círculo de Cultura permitiu identificar condutas de riscos das jovens e intervir por meio do diálogo, deixando que elas mesmas formassem opiniões.

\section{Terceiro encontro: Abordagem das doenças sexualmente transmissíveis}

0 primeiro passo desse encontro foi o esclarecimento do conceito de DST. Muitas meninas se surpreenderam com as fichas de cultura que abriam a discussão sobre as lesões e as formas de contágio das DST.

Durante as discussões que enfatizaram os meios de prevenção das DST, as meninas mantiveram-se atentas e participativas. Então, surgiram dúvidas que envolviam formas de contágio: (...) pega estas doenças por toalha? No banheiro público, pode pegar?

Diante dos questionamentos das meninas, observou-se 0 interesse de descobrir a existência de outra forma de contaminação por alguma DST. Discutiu-se a realidade dessas doenças de forma integrada com os meios de prevenção, fazendo com que elas repensassem seus conceitos e refletissem sobre essa realidade.

Ao permear a abordagem do papiloma vírus humano (HPV), observou-se que a maioria das jovens desconhecia sua 
existência e a forma de contágio. Sabe-se hoje que inúmeras mulheres são contaminadas por algum tipo de HPV. Muitas dessas lesões regridem, porém elas representam um fator contribuinte para o câncer cérvico-uterino, constituindo-se como um fator predisponente para a evolução de uma lesão benigna para uma maligna ${ }^{16}$. Assim, é necessário criar condições que façam com que as jovens reflitam sobre os riscos do contágio por esse vírus, considerando os fatores comportamentais em relação a sua própria saúde e de seus parceiros. Dessa forma, torna-se importante que essas jovens busquem realizar o exame de prevenção ginecológica, uma vez que este permite identificar as alterações cervicais. No meio do diálogo, fluiu a temática pré-natal em relação às DST: Tenho uma amiga que tem AIDS e ela teve um menino que não tem.

Inserido esse tema, discutiu-se a importância do pré-natal, já que o Ministério da Saúde preconiza que as gestantes o iniciem no primeiro trimestre, para proporcionar às futuras mães um pré-natal de qualidade, pois quanto mais precoce for diagnosticada a sífilis e/ou HIV, a partir dos exames de rotina do pré-natal, menor será o risco de transmissão vertical. Dessa forma, quanto antes as gestantes forem tratadas, serão evitadas a sífilis congênita e a transmissão do HIV para a criança ${ }^{17}$.

Portanto, pelo fato de o Círculo de Cultura ser dialogado, permitiu-se que fossem discutidos temas relacionados à vida das participantes do grupo, como também ao seu vínculo social. As colocações das adolescentes são pontos a serem discutidos, e devem ser enfatizados meios de ações de educação em saúde que as estimulem a refletir sobre suas condutas.

\section{Quarto encontro: discussões diversas}

Iniciou-se o diálogo com a reflexão da importância da prevenção ginecológica, surgindo alguns comentários:(...) para detectar doenças (...).Saber se tem alguma DST, inflamação. Observou-se que as jovens tinham uma percepção positiva da ida ao serviço de ginecologia, visto que as estratégias que rastreiam as DST assintomáticas, especialmente sífilis, gonorréia e clamídia em gestante e/ou adolescentes, são os serviços que executam atendimento ginecológico?

0 diálogo foi conduzido a partir da importância de procurar o serviço de saúde para fazer um exame de prevenção ginecológica, entretanto algumas meninas relataram que, mesmo sabendo desta necessidade, sentem medo e/ou vergonha de realizá-lo. Diante dessa discussão, uma jovem questionou: $\dot{E}$ verdade que perguntam se é virgem e falam na frente da mãe? Conversou-se sobre o direito ao sigilo e à privacidade. Diante desse comentário, constatou-se que as adolescentes, de modo geral, desconhecem que, para a assistência integral à saúde do adolescente, o Comitê da Criança recomenda que seja estimulado o respeito ao direito à privacidade, à confidencialidade e ao consentimento informado desse segmento, proporcionando e garantindo práticas de aconselhamento individual, bem como 0 acesso do adolescente à informação sobre sexualidade e reprodução e participação em programas relativos à saúde sexual e reprodutiva ${ }^{18}$.

Ainda no diálogo sobre esse tema, uma participante do grupo integrou-se à discussão, relatando: Acho isso uma besteira. A menina quando quer, faz do lado da mãe e ela nem vê. Diante dessa afirmação, observou-se que a busca de aventura e de prazer das adolescentes transpassa barreiras para realizar sua ação e, nessas questões de vulnerabilidade, se torna fundamental intervir de maneira dialógica sobre 0 método de prevenção das DST, favorecendo a discussão desse tema por meio do diálogo para gerar a conscientização.

A partir das discussões que englobam assuntos voltados para saúde da mulher, torna-se necessário aproximá-la ao serviço de saúde, tanto para o programa sobre planejamento familiar quanto para o exame de prevenção. 0 programa relacionado à saúde da mulher tem modificado efetivamente as taxas de incidência e mortalidade do câncer de colo do útero, devendo-se investir na preparação da população feminina através da educação em saúde, abordando a sua realização e a importância de fazê-lo ${ }^{19}$. Com este pensamento, foram explicados o material utilizado na consulta ginecológica e as etapas do exame. As adolescentes atentamente se integravam à explicação, tocavam no espéculo, na espátula de Ayre e na escovinha de campos da paz, sentindo os objetos, percebendo a flexibilidade, rigidez e, assim, retiravam suas dúvidas em relação à coleta citológica em meninas virgens e não virgens. Sobre o espéculo, foi comentado: Coloca seco? Sem nenhuma coisa. Abre assim? Mas é para ver o útero, aí tem que ser(...).

As discussões foram direcionadas de modo reflexivo, para que elas pudessem compreender e formar conceitos sobre o compromisso em procurar o serviço de ginecologia. Explicouse que não pode ser colocado nenhum lubrificante no espéculo porque será coletado material para análise, podendo alterar o resultado, e também que a própria vagina tem seu lubrificante natural. Enquanto se explicava a colocação do espéculo, discutiu-se sobre a elasticidade da vagina e a importância da realização do exame.

Com vistas à prevenção que engloba a saúde da mulher integramente, foi envolvido no diálogo o auto-exame das mamas, devido ao comentário de uma jovem que questionou como se faz o exame. Então, discutiu-se a importância de conhecer seu corpo, sua mama, para que, quando houver alguma alteração, ela seja identificada e, em seguida, seja procurado o serviço de saúde para investigá-la.

Em um momento do Círculo de Cultura, houve o questionamento: $O$ período fértil é sete dias antes e sete dias depois da menstruação? Embora nosso propósito fosse a prevenção de DST e de uma gravidez indesejada, não poderíamos deixar de discutir os métodos anticonceptivos, suscitados por essa jovem, visto que se tornam necessários as ações pela assistência geral da saúde sexual e reprodutiva e 0 acesso aos métodos anticonceptivo com a escolha livre e informada, como também a ação educativa com eixos norteadores do processo de trabalho com adolescentes ${ }^{19}$.

0 assunto sobre os métodos naturais despertou o interesse da jovem em conhecer seu corpo e compreender modificações, mas foi for temente estimulado o uso do preservativo em todas as relações sexuais por este ser o único método capaz de prevenir as DST e uma gravidez indesejada. 


\section{Quinto encontro: Avaliação do processo}

Iniciava-se o processo avaliativo em relação ao Círculo de Cultura, e as jovens estavam livres para relatar o que quisessem sobre o método aplicado, podendo ser o que elas tinham aprendido e/ou o que elas tinham gostado. Seus comentários foram categorizados em três aspectos: aprendizagem, temas/ temáticas abordados e estratégia de ensino.

Diante dos comentários das meninas na categoria aprendizagem, observa-se que elas destacaram os assuntos que envolviam as doenças que podem ter a via de transmissão vertical, o uso da camisinha, as DST e seus meios de prevenção, o conhecimento do seu corpo por meio da tabelinha, o autoexame das mamas e as implicações de uma gravidez precoce, visto assim, a reflexão sobre diversos assuntos que englobavam suas especificidades relacionadas à sua vida pessoal e social.

Dessa forma, elas não restringiram seu aprendizado somente às ações de prevenção das DST, também discutiram outros assuntos relacionados a essa temática, o que foi evidenciado pelos comentários: Tudo que eu aprendi vai ficar na minha mente pra vida toda. (...) quando a mãe estiver grávida e tiver AIDS, não deve amamentar o bebê. Esse projeto foi ótimo, ajudou a nos conscientizar sobre o uso da camisinha. Em toda relação sexual, usar camisinha, para não correr 0 risco de uma gravidez e de várias doenças. Eu aprendi, como se pega as doenças e conheci doenças como AIDS, sifilis, tudo um pouco, sobre tabelinha, gravidez, exame de mama (...)

$\mathrm{Na}$ categoria temas/temáticas abordados, elas relataram a forma de transmissão das DST e o modo de usar a camisinha e gostaram do esclarecimento de dúvidas acerca dos materiais utilizados da prevenção ginecológica, pois, muitas vezes, o desconhecimento da técnica do exame afasta a jovem de procurar o serviço de ginecologia, embora conheça a importância de realizá-lo. Foi dito também, sobre esses temas que envolvem a sexualidade das adolescentes, que nem sempre há pessoas que possam conversar e esclarecer suas dúvidas. Visto por seus relatos: (...) como se pega DST, conheci doenças que eu nunca tinha ouvido falar, HPV, como usar camisinha, como é a prevenção, como faz a tabelinha... O que eu mais gostei foi da explicação sobre a prevenção, o modo de usar o material... e também de ter tirado dúvidas e aprendido coisas que eu não sabia. Sobre essas conversas eu quase não tenho ninguém para tirar minhas dúvidas e também para me explicar.

$\mathrm{Na}$ terceira categoria, as meninas mencionaram a forma didática do Círculo de Cultura, contudo, elas conseguiram definila ao relatarem o termo diálogo, já que esta é a sua proposta. Demonstraram ter valorizado o método educativo e ter percebido de forma mais abrangente a formação do grupo, como a integração entre os seus participantes e os esclarecimentos de dúvidas por meio da reflexão, esta nomeada por uma jovem como debate; o incentivo, dito por outra, pode ser descrito como uma das conseqüências das discussões: (...) o diálogo, o debate entre as meninas, aprendemos um pouco de tudo.(...) todas as nossas perguntas foram esclarecidas e nós fomos bem tratadas, incentivando a gente a fazer prevenção e muito mais. Nunca participei dessas aulas e gostei, também dei valor porque todo mundo ficou junto, coisa que é muito difícil.

Assim, as ações de educação em saúde têm utilizado saberes de várias disciplinas para compreender e explicar as experiências humanas na formação de atitudes e comportamentos de saúde. A complexidade dos determinantes de saúde nos conduz à necessidade de investigações nesta área de conhecimento para promover ações educativas que sejam capazes de agir sobre o indivíduo, criando e ampliando suas potencialidades para inserir-se nos grupos que o englobem e em redes sociais, abrindo-se para experiências coletivas através do diálogo, construindo uma consciência coletiva para impulsionar mudanças e exercendo seu papel no controle social $^{20}$.

Observou-se que as três categorias se completam, pois os temas/temáticas abordados foram do interesse das jovens. A estratégia de ensino foi dialógica, para que elas se tornassem participativas nas discussões e para que se pudesse investigar sua sexualidade. Por fim, a aprendizagem foi uma conseqüência natural dos encontros, uma vez que a reflexão crítica realizada pelas adolescentes foi a partir dos temas relacionados a aspectos de sua juventude.

\section{CONSIDERAÇÕES FINAIS}

Do primeiro ao último encontro do Círculo de Cultura, foi possível identificar por meio da atividade educativa do enfermeiro como as adolescentes percebem a família, a escola e os amigos acerca da sexualidade na juventude, constatandose a necessidade de intervir a esse grupo a partir de suas necessidades específicas. Percebeu-se que as meninas associam o sexo à sexualidade de forma predominante e que tinham pouca compreensão das vulnerabilidades que estavam expostas numa prática sexual desprotegida.

Evidenciou-se que a execução do Círculo de Cultura permitiu que as adolescentes explorassem e discutissem sobre diversos temas que englobavam sua sexualidade, como tabelinha, prénatal, gravidez, como também é um momento para ações de educação em saúde. Esse fato favoreceu a harmonia e o envolvimento entre as participantes do círculo e o animador ao mediar o diálogo com temas que foram do seu próprio convívio e interesse. Observou-se como é importante o aprendizado emergir do próprio grupo, pois elas se percebem no seu contexto e puderam refletir sobre sua própria realidade. Vale ressaltar que pelo fato deste grupo ser composto apenas por meninas, estas se sentiram mais à vontade para abordarem assuntos peculiares do seu universo.

Constatou-se com esse estudo que são necessárias ações de educação em saúde, como o Círculo de Cultura, que propiciam o jovem expor suas dúvidas e conhecer os meios de prevenção, capacitando-o a repensar condutas, favorecendo uma melhor qualidade de vida e sendo um método eficaz para a aprendizagem. Nesse contexto, a Enfermagem preocupa-se com as ações de educação em saúde, podendo executar esta técnica para trabalhar com as jovens em diferentes setores e segmentos sociais com a meta de isentá-las de riscos. 


\section{Referências}

1. Torres CA, Beserra EP, Barroso MGT. Relações de gênero e vulnerabilidade às doenças sexualmente transmissíveis: percepções sobre a sexualidade dos adolescentes. Esc Anna Nery Rev Enferm 2007 jun; $11(2):$ 296-302.

2. Ministério da Saúde (BR). Secretaria de Vigilância em Saúde. Programa Nacional de DST e Aids. Manual de Bolso das Doenças Sexualmente Transmissíveis. Brasília (DF); 2006.

3. Rouqueirol MZ, Façanha MC, Veras FMF. Aspectos epidemiológicos das doenças transmissíveis. In: Rouqueirol MZ, Almeida Filho NA. Epidemiologia \& Saúde. 6ª ed. Fortaleza(CE): Medsi; 2003.

4. Beserra EP, Araújo MFM, Barroso MGT. Promoção da saúde em doenças transmissíveis: uma investigação em adolescentes. Acta Paul Enferm 2006; 9 (4): 402- 07.

5. Freire P. Educação como prática da liberdade. $23^{\mathrm{a}} \mathrm{ed}$. Rio de Janeiro (SC): Paz e Terra; 1999.

6. Brandão CR. Que é método Paulo Freire. 25ª ed. São Paulo (SP): Brasiliense; 2004.

7. Trentini M, Paim L. Pesquisa em enfermagem: uma modalidade convergente-assistencial. Florianópolis(SC): Ed UFSC; 1999.

8. Carvalho A, Pinto MV. Ser ou não ser...Quem são os adolescentes? In: Carvalho FS, Guimarães M, organizadores. Adolescência. Belo Horizonte (MG): Ed UFMG; 2002.

9. Belo MAV, Silva JLP. Conhecimento, atitude e prática sobre métodos anticoncepcionais entre adolescentes gestantes. Rev Saude Publica 2004; 38 (4): 479-87.

10. Heidemann, M. Adolescência e saúde: uma visão preventiva: para profissionais de saúde e educação. Petrópolis (RJ): Vozes; 2006.
11. Passetti E. Conversação libertária com Paulo Freire. São Paulo (SP): Imaginário; 1998.

12. Taquette SR, Vilhena MM, Paula MC. Doenças sexualmente transmissíveis e gênero: um estudo transversal com adolescentes no Rio de Janeiro. Cad Saúude Publica 2004; 20 (1): 282-90.

13. Freire $P$. Ação cultural para a liberdade e outros escritores. $10^{a}$ ed. São Paulo (SP): Ed Paz e Terra; 2002.

14. Carvalho AM, Rodrigues CS, Medrado KS. Oficinas em sexualidade humana com adolescentes. Est Psicol 2005; 10 (3): 377-84.

15. Zagury T. 0 adolescente por ele mesmo. $11^{\text {a }}$ ed. Rio de Janeiro (RJ): Record; 2000.

16. Passos MRL. Doenças sexualmente transmissíveis: se educar, dá para evitar. Rio de Janeiro (RJ): Revinter; 2001.

17.Ministério da Saúde (BR). Secretaria de Atenção à Saúde. Departamento de Ações Programática Estratégicas. Área Técnica de Saúde da Mulher. Pré-natal e Puerpério: atenção qualificada e humanizada - manual técnico Brasília (DF); 2005.

18. Ventura M, Correa S. Adolescência, sexualidade e reprodução: construções culturais, controvérsias normativas, alternativas interpretativas. Cad. Saude Púublica 2006; 22 (7): 1505-509.

19. Secretária da Saúde (CE) Saúde reprodutiva e sexual: um manual para atenção primária e secundária-nível ambulatorial. Fortaleza (CE): SESA-CE; 2002.

20. Frota MA, Silva RM, Nations MK, Landim FLP, Monte CG, Varela ZM. de V. Redes de suporte social: uma proposta educativa para a saúde da comunidade. In: Barroso MGT, Vieira NFC, Varela ZMV, organizadores. Educação em saúde no contexto da promoção humana. Fortaleza (CE): Demócrito Rocha; 2003. 